\title{
OBTENÇÃO DE FILMES ESPESSOS DE SELENETO DE COBRE SOBRE CARBONO VÍTREO, OURO, TITÂNIO E COBRE
}

Adriano César Rabelo, Tatiane Moraes Arantes e Otávio Luiz Bottecchia*

Instituto de Química, Universidade Federal de Uberlândia, Av. João Naves de Ávila, 2160, 38408-902 Uberlândia - MG, Brasil

Recebido em 11/10/05; aceito em 31/5/06; publicado na web em 28/11/06

\begin{abstract}
OBTAINING COPPER SELENIDE THICK FILMS ON VITREOUS CARBON, GOLD, TITANIUM AND COPPER. Copper selenide (berzelianite) films were prepared on the title substrates using the chemical bath deposition technique (CBD). Film composition was determined by energy dispersion of $\mathrm{x}$-rays. The kinetics of film growth is parabolic and film adherence limits the film thickness. On titanium, copper selenide forms islands that do not completely cover the surface, unless the substrate is prepared with a tin oxide layer; film composition also depends on the titanium oxide layer. On vitreous carbon, CBD and mechanical immobilization techniques lead to films with similar resistances for the electron transfer across the film/substrate interface. On gold, composition studies revealed that film composition is always the same if the $\mathrm{pH}$ is in the range from 8 to 12 , in contrast to films prepared by an ion-ion combination route. On copper, a new procedure for obtaining copper selenide films as thick as $5 \mu \mathrm{m}$ has been developed.
\end{abstract}

Keywords: copper selenide; thin films; semiconductor.

\section{INTRODUÇÃO}

Seleneto de cobre é um material de interesse na produção de dispositivos fotovoltaicos. Entre outros calcogenetos metálicos, é um potencial candidato na substituição do silício, cujo custo dificulta a popularização do uso de energia solar na geração alternativa de energia elétrica de pequena escala. A escolha de materiais apropriados que substituam o silício com rendimento quântico competitivo, a otimização dos métodos preparativos e a redução de outros possíveis custos, além do emprego que o seleneto de cobre encontra em dispositivos eletrônicos e optoeletrônicos ${ }^{1}$, constituem vasta área de pesquisa ${ }^{2}$. No presente trabalho, as condições de obtenção de filmes de $\mathrm{Cu}_{2-\mathrm{x}} \mathrm{Se}$ foram investigadas com objetivo de obter filmes aderentes com espessura nominal superior a $2 \mu \mathrm{m}$.

O seleneto de cobre é um semicondutor que aparece em diferentes composições estequiométricas $\left(\mathrm{Cu}_{2} \mathrm{Se}, \mathrm{Cu}_{3} \mathrm{Se}_{2}, \mathrm{CuSe}\right.$, e $\left.\mathrm{CuSe}_{2}\right)$, não estequiométricas $\left(\mathrm{Cu}_{2-\mathrm{x}} \mathrm{Se}\right)$ e em várias formas cristalográficas ${ }^{3}$. As propriedades destes semicondutores aparentemente resultam de defeitos da estrutura oriundos do desvio estequiométrico. A largura de banda ("band gap") dos selenetos de cobre varia de 1,4 a 2,2 $\mathrm{eV}^{4,5}$. Garcia et al. ${ }^{4}$ distinguem a largura de banda direta da indireta, que é 2,2 e 1,4 eV, respectivamente. $\mathrm{Cu}_{2-\mathrm{x}}$ Se melhora o rendimento de fotocélulas à base de n-Si quando usado como fresta ("window material"), material usado para absorver a radiação não absorvida por camadas de semicondutores na heterojunção ${ }^{4} \cdot \mathrm{Cu}_{1,8} \mathrm{Se}$ é supercondutor iônico ${ }^{6}$ e é empregado em importante classe de componentes da microeletrônica, os diodos de Schottky ${ }^{7}$. Zhang et al. ${ }^{8}$ usaram-no em camadas fotoabsorventes de células solares. Por fim, seleneto de cobre é também um precursor na síntese do $\mathrm{CuInSe}_{2}$, que foi o primeiro material que despertou atenção na substituição do silício em dispositivos fotovoltaicos ${ }^{2,9}$. Compostos ternários, como $\mathrm{CuInSe}_{2}$, já foram empregados em células solares com $18 \%$ de eficiência ${ }^{10,11}$. Ward et al. ${ }^{12}$ melhoraram esta marca para $21 \%$. Estes valores são notáveis em vista do rendimento teórico máximo ca. 30\%, uma característica intrínseca destes sistemas ${ }^{13}$. Empresas como a $\mathrm{Nedo}^{14}$ estão estimuladas a produzir e testar células à base de CIGS

*e-mail: otavio@ufu.br (seleneto de cobre, índio e gálio). Recentemente, a Universidade de Tóquio lançou um satélite experimental, cujo principal objetivo é comparar a eficiência das células solares CIGS com células solares à base de arseneto de gálio ${ }^{15}$.

$\mathrm{O}$ uso destes materiais na forma de filmes finos significa vantagem econômica por causa da pequena quantidade de material empregado por unidade de superfície. A obtenção de filmes relativamente mais espessos possibilita arcar com perdas ocasionadas por tratamento posterior (por ex., "chemical etching") e, ainda assim, dispor de um filme com espessura apropriada.

A preparação de seleneto de cobre é possível por grande número de técnicas. $\mathrm{O}$ interesse neste trabalho é usar uma técnica simples e de baixo custo. A deposição por banho químico satisfaz este pré-requisito, além de reproduzir com relativa facilidade em larga escala os resultados obtidos em escala de laboratório ${ }^{16}$. Conhecida como CBD ("bath chemical deposition"), a deposição por banho químico, DBQ, consiste na reação de oxidação-redução entre íons, ou entre um íon e um substrato ${ }^{3,17}$. Controlando o $\mathrm{pH}$, Dhanam et al. ${ }^{18}$ conseguiram obter seletivamente $\mathrm{Cu}_{3} \mathrm{Se}_{2}$ ou $\mathrm{Cu}_{2-\mathrm{x}}$ Se pela técnica de reação íon-íon.

Neste trabalho foi utilizado cobre metálico como reagente:

$(2-x) \mathrm{Cu}+\mathrm{SeSO}_{3}^{2-} \rightarrow \mathrm{Cu}_{2-\mathrm{x}} \mathrm{Se}+\mathrm{SO}_{3}^{2-}$

$\mathrm{O} \mathrm{Cu}_{2-\mathrm{x}} \mathrm{Se}$ é praticamente insolúvel em água e deposita-se sobre o cobre metálico assim que é formado. Novas interfaces aparecem: a interface entre o $\mathrm{Cu}_{2-x}$ Se e a solução e a interface $\mathrm{Cu}_{2-x}$ Se e o substrato. $\mathrm{O} \mathrm{Cu}_{2-x} \mathrm{Se}$ forma uma barreira entre o cobre e a solução. Entretanto, o íon cobre difunde-se através do filme desde o substrato até chegar na interface com a solução ${ }^{19}$. Este processo permite o crescimento do filme até certo ponto. A origem do despelamento nos procedimentos aqui descritos parece estar relacionada com a acomodação do filme simultaneamente à difusão de íons cobre. Este modelo de crescimento motivou a investigação da acomodação do filme antes de permitir seu crescimento em uma etapa subseqüente. A metodologia, aqui denominada deposição seriada, consiste em impor um período de descanso, $\mathrm{t}_{\mathrm{D}}$, alternado a um período de crescimento, $\mathrm{t}_{\mathrm{DBQ}}$. Durante o tempo de descanso, o filme é retirado 
da mistura reacional e deixado exposto ao ar ou em água destilada. Depois é novamente levado à mistura reacional, e assim sucessivamente, tantas vezes quanto necessário até a obtenção da espessura desejada. Uma técnica de deposição seriada foi usada por Pathan et $a l{ }^{20}$. Entretanto, a técnica aqui proposta é distinta. Aquela técnica consiste na adsorção de um precursor de cobre(II) aquoso seguida de precipitação, usando soluções distintas em cada etapa. No presente trabalho, a fonte de cobre está no próprio substrato na forma sólida e a deposição seriada é usada como recurso para compensar a demora da difusão no estado sólido. A forma de representação do crescimento do filme na técnica de DBQ ou na técnica de deposição seriada é idêntica, através do gráfico da espessura ou da massa do material formado no filme em função de $t_{\mathrm{DBQ}} \mathrm{O}$ tempo do experimento na deposição seriada é, obviamente, maior.

Técnicas eletroquímicas permitem a caracterização dos filmes de seleneto de cobre. Lange, Lovric e Scholz ${ }^{21}$ propuseram um modelo para a redução eletroquímica do seleneto de cobre em condições de varredura linear. De acordo com este modelo, aqui denominado de modelo LLS, a relação entre o potencial de pico catódico, $E_{m a x}$, e a carga sob o pico, $Q$, é dada por:

$$
E_{\max }=E_{s t}-\frac{v}{b} \ln \left(1+\frac{b Q}{a}\right)-R^{*} b Q-R^{*} a
$$

em que: $E_{s t}$ é o potencial inicial; $n$, a velocidade de varredura; $R^{*}$, resistência de transferência eletrônica entre substrato e filme; $b=$ $a n F v /(R T) ; a=n F S K_{\text {red }} \exp \left[-\alpha n E_{s t} /(R T)\right] ; \alpha$ é o coeficiente de transferência; $F$, a constante de Faraday; $n$, o número de elétrons transferidos (neste caso, um elétron); $S$, a superfície do eletrodo; $K_{\text {red }}$, a constante heterogênea de transferência de carga; $R$, a constante dos gases ideais e $T$, a temperatura termodinâmica. Lange $e t$ $a l .{ }^{21}$ mostraram que a Equação 2 pode ser simplificada, de modo a resultar $\mathrm{d} E_{\max } / \mathrm{d} Q \approx-2 R^{*}$. Este resultado não se deixa influenciar pela condutividade da solução, provocada por uma quantidade adicional de eletrólito inerte. Assim, espera-se do gráfico do potencial $E_{\max }$ em função da carga $Q$ uma relação linear, cujo coeficiente angular é proporcional à resistência de transferência eletrônica.

\section{PARTE EXPERIMENTAL}

Os filmes foram preparados pela reação de cobre metálico em solução aquosa de selenossulfato de sódio e sulfito de sódio. $\mathrm{O}$ selenossulfato de sódio foi sintetizado seguindo o procedimento de Bhattacharya ${ }^{22}$, armazenado em solução aquosa na presença de sulfito de sódio 0,10 a $0,20 \mathrm{~mol} \mathrm{~L}^{-1}$ para prevenir sua decomposição e padronizada por gravimetria, precipitando o selênio com excesso de solução de ácido nítrico. Todos os reagentes utilizados eram de pureza analítica.

A cinética de crescimento do filme foi acompanhada em função do tempo de banho por pesagem do substrato. A massa do filme, se uniformemente distribuído na área geométrica do substrato, permite estimar a espessura. A área geométrica do substrato foi inicialmente de $1 \mathrm{~cm}^{2}$ aumentada para $6 \mathrm{~cm}^{2}$ para melhorar a precisão das medidas gravimétricas. A espessura nominal foi calculada a partir da densidade do seleneto de cobre ${ }^{23}$ igual a $6,749 \mathrm{~g} \mathrm{~cm}^{-3}$. Foram investigados efeitos da rugosidade e do tratamento da superfície do substrato. Testou-se o efeito da hidrazina no crescimento do seleneto de cobre, seguindo procedimento similar ao de Doña e Herrero ${ }^{24}$ na síntese de filmes finos de sulfeto de zinco. Substratos rugosos foram obtidos com jato de areia.

Cobre metálico exposto ao ar produz em sua superfície quase que instantaneamente uma camada de óxido de cobre. Embora esta camada seja de uns poucos nanômetros de espessura ${ }^{25}$,
Schimmel et al. ${ }^{26}$ verificaram que esta camada influencia a morfologia de filmes de sulfeto de cobre. Para investigar se este fenômeno também se manifesta nos filmes de seleneto de cobre, a superfície do cobre foi decapada, submetendo-a a uma corrente catódica de $0,8 \mathrm{~A} \mathrm{dm}^{-2}$ por 2 min em solução de ácido sulfúrico 10 $\mathrm{g} \mathrm{L}^{-1}$ e imediatamente transferido sem lavagem para uma solução de sulfato de cobre $200 \mathrm{~g} \mathrm{~L}^{-1}$ contendo ácido sulfúrico $10 \mathrm{~g} \mathrm{~L}^{-1}$. Alternativamente, a decapagem foi realizada em solução de sulfito de sódio $0,1 \mathrm{~mol} \mathrm{~L}^{-1}\left(0,8 \mathrm{~A} \mathrm{dm}^{-2}\right)$. Neste caso, a adição de selenossulfato de sódio na concentração desejada foi feita sob polarização catódica, para depois se desligar o galvanostato. As concentrações finais de sulfito de sódio e selenossulfato de sódio foram 0,10 e de 8,0 a $15,4 \mathrm{mmol} \mathrm{L}^{-1}$, respectivamente.

A eletrodeposição de cobre sobre os diversos substratos, quando necessária, foi feita usando banho de sulfato de cobre em meio de ácido sulfúrico, comum na galvanoplastia ${ }^{27}$. O tempo de eletrodeposição de cobre foi variado de acordo com a espessura desejada.

$\mathrm{Na}$ caracterização por voltametria de varredura linear $(50 \mathrm{mV} / \mathrm{s})$, os filmes de seleneto de cobre foram preparados sobre eletrodo de carbono vítreo $\left(0,070 \mathrm{~cm}^{2}\right.$ de área geométrica) recoberto com cobre eletrodepositado. Os eletrólito de suporte e eletrodo de referência eram ácido perclórico $0,10 \mathrm{~mol} \mathrm{~L}^{-1}$ e $\mathrm{Ag} / \mathrm{AgCl} /(\mathrm{KCl}+\mathrm{AgCl}$ saturados). $\mathrm{O}$ eletrodo auxiliar em todos os experimentos era platina.

Prepararam-se filmes de seleneto de cobre sobre titânio $\left(1,0 \mathrm{~cm}^{2}\right.$ de área geométrica). Para estudar a influência da camada de óxido de titânio na superfície do eletrodo, o filme foi crescido em três diferentes situações: sobre titânio sem tratamento; sobre titânio levado à mufla a uma temperatura de $450{ }^{\circ} \mathrm{C}$ por $1 \mathrm{~h}$, com objetivo de aumentar a camada de óxido de titânio; e sobre titânio fervido com ácido oxálico $10 \%$ por $10 \mathrm{~min}$, com objetivo de diminuir a camada de óxido de titânio. A limpeza da superfície (seqüencialmente detergente, $\mathrm{NaOH}$, isopropanol, detergente em banho ultra-sônico e água destilada), o tempo de eletrodeposição de cobre (30 s) e o tempo de banho em selenossulfato (30 min) foram os mesmos nos três casos. Para investigar a influência do óxido de estanho(IV), o titânio foi pincelado com solução de cloreto estanoso $0,01 \mathrm{~mol} \mathrm{~L}^{-1}$ e levado à mufla por 1 h, a uma temperatura de $450{ }^{\circ} \mathrm{C}$.

Estudos de microscopia eletrônica de varredura e estudos por energia dispersiva de raio-x foram realizados em São Carlos, no Instituto de Física da Universidade de São Paulo. As técnicas eletroquímicas foram realizadas usando um potenciostato/ galvanostato Princeton \& Applied Research, modelo 273 ou um galvanostato Radelkis $\mathrm{OH} 405$.

\section{RESULTADOS E DISCUSSÃO}

O desenvolvimento da reação entre cobre e selenossulfato de sódio é visível a olho nu. Uma placa de cobre com sua coloração característica enegrece gradativamente assim que entra em contato com a solução. A massa do filme aumenta com o tempo de banho e, conseqüentemente, varia também sua espessura. Forma-se um filme escuro. A coloração escura desaparece no prazo de alguns segundos a 1 min, expondo novamente a coloração similar à do cobre metálico. Após este tempo de indução, escurece de forma definitiva. Lakshmi et $a l .{ }^{5}$ descrevem o seleneto de cobre por uma coloração marrom avermelhada $\left(\mathrm{Cu}_{2-\mathrm{x}} \mathrm{Se}\right)$ ou verde azulado $\left(\mathrm{Cu}_{3} \mathrm{Se}_{2}\right)$, enquanto que Dhanam et al..$^{18} \mathrm{o}$ descrevem como marrom esverdeado. Aqueles autores enfatizam que as condições experimentais de preparação do filme se refletem na cor do filme formado.

A análise por difração de raios-x revela que a composição dos filmes formados por DBQ consiste em berzelianita, $\mathrm{Cu}_{2-\mathrm{x}} \mathrm{Se}^{23}$. A composição dos filmes obtida por energia dispersiva de raios-x concorda com este resultado. 


\section{Crescimento sobre carbono vítreo}

O uso de carbono vítreo permite a comparação direta de resultados com os de outros autores. A Figura 1 apresenta voltamogramas típicos com um pico de redução do $\mathrm{Cu}_{2-\mathrm{x}} \mathrm{Se}$ em ácido perclórico $0,10 \mathrm{~mol} \mathrm{~L}^{-1}$. Os picos menores correspondem a filmes com menores espessuras. A redução corresponde à formação de cobre metá$\operatorname{lico}^{23}$.

$\mathrm{Cu}_{2-\mathrm{x}} \mathrm{Se}($ sólido $)+2 \mathrm{e} \rightarrow(2-\mathrm{x}) \mathrm{Cu}($ sólido $)+\mathrm{Se}^{2-}($ aquoso $)$

Como o pH no eletrólito é ácido, o ion $\mathrm{Se}^{2-}$ naturalmente origina HSe'. O seleneto (e o $\mathrm{HSe}^{-}$) difunde-se na solução e não permite que a reação eletroquímica ocorra no sentido contrário na varredura de volta (não mostrada).

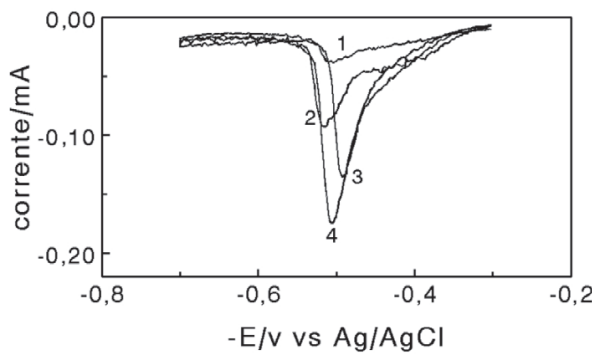

Figura 1. Voltamogramas de varredura linear do seleneto de cobre sobre carbono vítreo em ácido perclórico aquoso $0,10 \mathrm{~mol} \mathrm{~L}^{-1}$. Picos maiores correspondem a eletrodos recobertos com filmes mais espessos. Curva 1: $t_{\text {eletrólise }}=30 \mathrm{~s}, t_{D B Q}=30 \mathrm{~min}$; curva $2: t_{\text {eletrólise }}=20 \mathrm{~s}, t_{D B Q}=20 \mathrm{~min}$; curva 3: $t_{\text {eletrólise }}=10 \mathrm{~s}, t_{D B Q}=10 \mathrm{~min}$; curva $4: t_{\text {eletrólise }}=15 \mathrm{~s}, t_{D B Q}=15 \mathrm{~min}$

De acordo Lange et $a l .^{21}$, a posição exata do pico depende, entre outros fatores, da carga sob o pico voltamétrico. Na preparação dos filmes, o tempo de DBQ, $\mathbf{t}_{\mathrm{DBQ}}$, controla a reação de formação de seleneto de cobre, enquanto que o tempo de eletrodeposição, $\mathbf{t}_{\text {eletrólise' }}$, controla a formação de cobre metálico sobre o carbono vítreo. O sinal voltamétrico não aparece no intervalo de potencial usado por Lange et al. ${ }^{21}$ quando a conversão do cobre em $\mathrm{Cu}_{2-\mathrm{x}}$ Se for apenas parcial. $\mathrm{O}$ sinal aparece distorcido em potenciais próximos a $-1,0 \mathrm{~V}$.

Os resultados obtidos são similares aos resultados de Lange et $a l{ }^{21}$ (Figura 2). A resistência de transferência eletrônica entre o filme de $\mathrm{Cu}_{2-x}$ Se e carbono vítreo, $\mathrm{R}^{*}$, foi calculada a partir do modelo LLS. Os coeficientes angulares são similares e levam ao valor de $30 \Omega$ para a resistência de transferência eletrônica entre o filme de $\mathrm{Cu}_{2-\mathrm{x}} \mathrm{Se}$ e o carbono vítreo.

Esperava-se que o procedimento adotado neste trabalho levasse a um aperfeiçoamento em relação ao procedimento adotado por Lange et $a l .{ }^{21}$. O método de imobilização do filme de $\mathrm{Cu}_{2-\mathrm{x}} \mathrm{Se}$ por

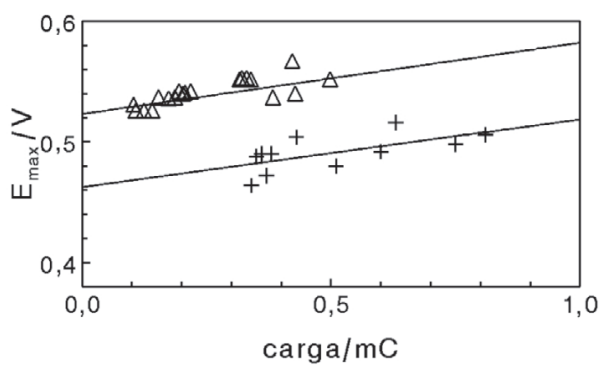

Figura 2. Aplicação do modelo LLS aos filmes de seleneto de cobre obtidos após eletrodeposição de cobre metálico sobre carbono vítreo. $\Delta$ : resultados da ref. 21 ; +: resultados deste trabalho eletrodeposição seguido de DBQ deveria garantir um filme mais compacto, favorecendo a transferência eletrônica entre carbono vítreo e o $\mathrm{Cu}_{2-\mathrm{x}} \mathrm{Se}$. Considerando esta resistência ôhmica, o resultado aqui obtido leva a concluir que ambos os procedimentos são similares.

É interessante fazer uma digressão sobre o mecanismo de decomposição de $\mathrm{Cu}_{2 \times}$ Se durante a varredura de potencial para se ter uma imagem do processo de redução. Imagine-se a região de contato do filme de $\mathrm{Cu}_{2-\mathrm{x}} \mathrm{Se}$ com o substrato. Por simplicidade, o filme e o substrato foram representados na Figura 3 como camadas compactas, uma sobre a outra. Duas interfaces são características: a interface $\mathrm{Cu}_{2-\mathrm{x}} \mathrm{Se} /$ solução e a interface $\mathrm{Cu}_{2-x}$ Se/carbono vítreo. Sob ação de um potencial elétrico, inicia-se a formação de cobre metálico através da semireação mostrada anteriormente. A acomodação do cobre metálico formado poderia seguir distintos caminhos: pode acomodar-se na interface $\mathrm{Cu}_{2-x} \mathrm{Se} /$ solução (hipótese $\mathrm{A}$ ) ou na interface $\mathrm{Cu}_{2-\mathrm{x}} \mathrm{Se} /$ carbono vítreo (hipótese B). Há dois motivos para pensar que a hipótese A seja mais provável. Um motivo é que, segundo Braune, Hellwege e $\mathrm{Kahn}^{28}$, $\mathrm{Se}(-\mathrm{II})$ não se difunde através do $\mathrm{Cu}_{2-\mathrm{x}} \mathrm{Se}$ (assim como $\mathrm{Se}(-\mathrm{II})$ não se difunde em $\left.\mathrm{Cu}_{2-\mathrm{x}} \mathrm{S}^{19}\right)$. O outro motivo é que o $\mathrm{Cu}_{2-\mathrm{x}} \mathrm{Se}$ sobre cobre não apresenta sinal voltamétrico no intervalo de potencial da Figura 1. Com o filme de cobre formando-se sobre o $\mathrm{Cu}_{2-x} \mathrm{Se}$, o $\mathrm{Se}(-\mathrm{II})$ não precisa se difundir pela fase sólida, pois já se encontra em contato com a solução. A hipótese A, portanto, proporciona uma explicação consistente. Já a hipótese $\mathrm{B}$ contraria os dois motivos mencionados porque o cobre, formando-se na interface $\mathrm{Cu}_{2-\mathrm{x}} \mathrm{Se} /$ carbono vítreo, criaria duas novas interfaces $\left(\mathrm{Cu} / \mathrm{Cu}_{2-\mathrm{x}} \mathrm{Se}\right.$ e $\mathrm{Cu} /$ carbono vítreo). $\mathrm{O}$ crescimento do cobre, então, requereria que o $\mathrm{Se}(-\mathrm{II})$ formado na nova interface $\mathrm{Cu}$ / carbono vítreo se difundisse através do $\mathrm{Cu}_{2-\mathrm{x}}$ Se para poder chegar na solução, contrariando Braune, Hellwege e Kahn.

\section{Hipótese A}

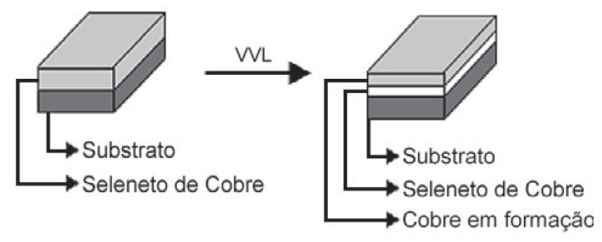

Hipótese B

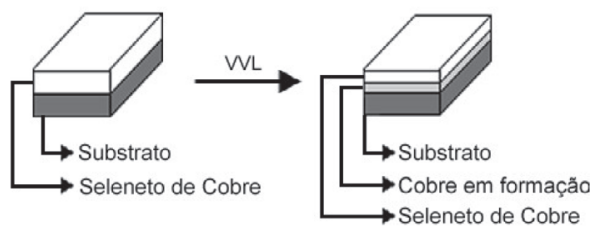

Figura 3. Modelo simplificado da formação da camada de cobre pela redução do seleneto de cobre durante a voltametria de varredura linear, VVL. Hipótese A: cobre formado na interface $\mathrm{Cu}_{2-x}$ Se/solução. Hipótese B: cobre formado na interface $\mathrm{Cu}_{2-x} \mathrm{Se} /$ substrato

\section{Crescimento sobre ouro}

O uso de ouro permite a investigação da composição do filme por energia dispersiva de raios-x, que não foi adequada com os outros substratos. Para investigar o efeito do $\mathrm{pH}$ sobre a composição do filme, o substrato de ouro foi o mais adequado dentre os materiais disponíveis. Filmes preparados sobre ouro em solução de selenossulfato de sódio com pH 8 apresentaram composição 65,5\% de $\mathrm{Cu}$ e $34,5 \%$ de $\mathrm{Se}$ em peso. Quando preparados nas mesmas condições, porém com $\mathrm{pH} 12$ ajustado com $\mathrm{NaOH}$, a composição foi praticamente a mesma $(64,2 \%$ de $\mathrm{Cu}$ e $35,8 \%$ de $\mathrm{Se}$ em peso). Por- 
tanto, o pH não influencia na composição do filme. Isto faz do DBQ uma alternativa em relação ao procedimento de Lakshmi et al.$^{29}$. Estes autores propõem uma metodologia que permite obter tanto umangita como berzelianita controlando o $\mathrm{pH}$ da solução. Tal procedimento pode ser vantajoso no que diz respeito ao controle do produto obtido. Por outro lado, pode ser desvantajoso com relação à possibilidade de obtenção de uma mistura de compostos no filme.

$\mathrm{O}$ filme obtido no presente trabalho parece corresponder à berzelianita rica em cobre. Cobre que não reage com íon selenossulfato impede o aparecimento de um pico voltamétrico. Isto foi contornado controlando-se o tempo de DBQ. A resistência de transferência eletrônica entre o filme e o ouro pelo modelo de LLS é $0,8 \Omega$, usando $100 \mathrm{~mA}$ na eletrodeposição de cobre sobre uma lâmina de ouro com $0,5 \mathrm{~cm}^{2}$. O contato do filme sobre ouro é, portanto, mais condutivo que o contato sobre carbono vítreo.

\section{Crescimento sobre titânio}

As excelentes propriedades mecânicas de diversos filmes preparados sobre titânio, usados em outras aplicações, estimularam as investigações sobre este substrato na busca de melhor aderência. O óxido de titânio, formado no titânio exposto ao ar, exerce uma influência significativa nas propriedades dos filmes de seleneto de cobre. O óxido de titânio pode ser crescido aquecendo-se o titânio na presença do oxigênio do ar a $450{ }^{\circ} \mathrm{C}$, ou pode ser retirado tratando-se o titânio com ácido oxálico.

No titânio sem qualquer tratamento, o seleneto de cobre formase como glóbulos não uniformes, originando pequenos aglomerados de ilhas com extensão de uns poucos micrometros, insuficientes para cobrir toda a superfície do titânio. Apresenta $86 \%$ de cobre, o que denuncia a conversão apenas parcial do cobre em seleneto de cobre. Provavelmente, trata-se de cobre recoberto com seleneto de cobre. Tais filmes não originaram pico na voltametria de varredura linear, similar ao que se observou em carbono vítreo.

No titânio levado à mufla, a morfologia é similar, exceto que os aglomerados se reúnem formando agrupamentos irregulares (Figura 4a).

Tanto no titânio sem tratamento, quanto no titânio levado à mufla na presença de oxigênio ou no titânio tratado com ácido oxálico, o filme de seleneto de cobre não recobre toda a superfície e despelase facilmente. Quanto maior a espessura de cobre eletrodepositado, pior é a aderência do seleneto de cobre.

O óxido de titânio desfavorece a obtenção do filme, possivelmente porque sua baixa condutividade elétrica desfavorece a eletrodeposição homogênea do cobre. Melhorando a condutividade da superfície, espera-se melhorar a distribuição de cobre e, conseqüentemente, a do filme também. Uma possibilidade para melhorar a condutividade elétrica da superfície é recobrí-la com óxido de estanho. Esta abordagem levou à melhora da aderência de seleneto de cobre sobre o vidro condutor ${ }^{5}$. Tal melhora também ocorreu sobre o titânio. A morfologia do filme (Figura 4b), embora porosa, apresenta recobrimento uniforme e homogêneo, com composição $61,8 \mathrm{~mol} \%$ de cobre e 38,2 mol\% de selênio, correspondente a $\mathrm{Cu}_{1,62} \mathrm{Se}$. Tais filmes apresentam picos na voltametria de varredura linear similares aos obtidos em carbono vítreo e ouro. Tempo de DBQ muito curto não permite a conversão completa do cobre em seleneto de cobre. Tempo de DBQ muito longo leva ao despelamento do filme. No intervalo intermediário, verificou-se uma correlação entre carga e potencial de pico, que determina a resistência de transferência eletrônica entre o filme e o titânio em $0,4 \Omega$. Este valor é menor que em filmes sobre de carbono vítreo (30 $\Omega$ ) e sobre ouro $(0,8 \Omega)$. Portanto, o contato do filme pode ser considerado adequado para aplicações que requerem boa condutividade elétrica, com a ressalva de que os filmes não são espessos (menos de $1 \mu \mathrm{m}$ ) e são pouco aderentes.

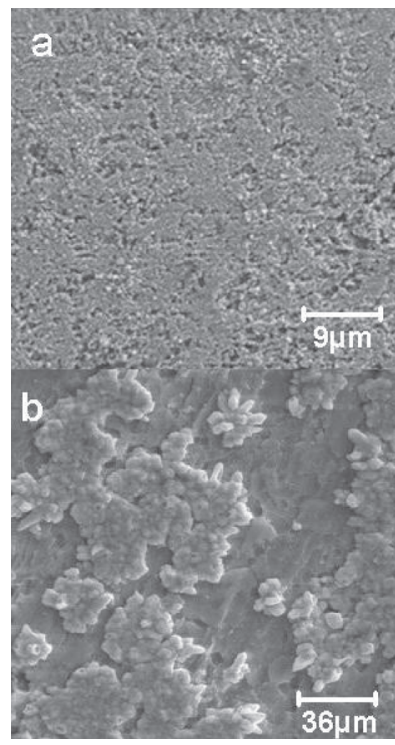

Figura 4. Imagem da superfície do seleneto de cobre sobre titânio: (a) substrato previamente fervido com ácido oxálico. Os aglomerados constituemse de seleneto de cobre. Entre os aglomerados está exposta a superfície do titânio. Aresta: $45 \mu \mathrm{m}$; (b) substrato previamente recoberto com dióxido de estanho. Aresta: $180 \mu \mathrm{m}$

\section{Crescimento sobre cobre}

Cobre foi uma escolha apropriada para preparar seleneto de cobre porque é o próprio reagente e pelo menor custo comparativamente aos outros substratos. $\mathrm{O}$ crescimento de filmes obedece à lei de Wagner ${ }^{30}$, $\delta=a t^{1 / 2}$, em que $a$ é constante, $\delta$ representa a espessura do filme e $t$ é o tempo contado após o tempo de indução. O parâmetro $a$ depende da temperatura, da concentração de selenossulfato e do gradiente de atividade do íon cobre no filme entre as interfaces filme/solução e filme/substrato ${ }^{19}$. No presente trabalho, usando selenossulfato de sódio $7,1 \mathrm{mmol} \mathrm{L}^{-1}$ e $25^{\circ} \mathrm{C}$, o valor de $a$ é cerca de $0,10 \mathrm{mg} \mathrm{cm}^{-2} \mathrm{~min}^{-1 / 2}$. Filmes mais espessos $(1,1 \mu \mathrm{m})$ só puderam ser preparados nas superfícies mais rugosas ${ }^{31}$. Esta melhor aderência à superfície rugosa possivelmente se deve a uma melhor ancoragem mecânica entre o filme e o substrato. Nos substratos mais lisos, o filme desprende-se quando atinge cerca de $0,5 \mu \mathrm{m}$ de espessura.

Sobre cobre liso sem decapagem eletroquímica, o filme apresenta despelamento. $\mathrm{O}$ despelamento origina-se nos primeiros estágios da formação do filme (Figura 5a) e não ocorre nas mesmas condições se for feita a decapagem. No substrato rugoso, a decapagem exerce pouca ou nenhuma influência tanto sobre o despelamento quanto sobre a morfologia da superfície do filme de seleneto de cobre. De modo geral, a aderência no substrato rugoso é consideravelmente melhor que no substrato liso.

A decapagem não eletroquímica da superfície do cobre rugoso (com ácido nítrico concentrado, $5 \mathrm{~s}$, seguido de hidróxido de amônio concentrado, $10 \mathrm{~min}$ ) produz superfícies completamente isentas de quaisquer tipos de manchas visíveis a olho nu. Este resultado dificilmente é obtido somente com hidróxido de amônio. O ácido nítrico deve ser usado com cautela, pois pode diminuir a rugosidade.

As características do filme de seleneto de cobre não melhoraram com adição de hidróxido de amônio no meio reacional. A adição de hidrazina não melhora a aderência do $\mathrm{Cu}_{2-\mathrm{x}} \mathrm{Se}$, ao contrário do que Doña e Herrero ${ }^{24}$ relataram sobre o seleneto de zinco.

Sobre cobre rugoso, o crescimento do filme segue a lei de Wagner até cerca de $50 \mathrm{~min}$. Após este tempo, o aumento da massa de seleneto de cobre é superior ao esperado pela lei de Wagner. 


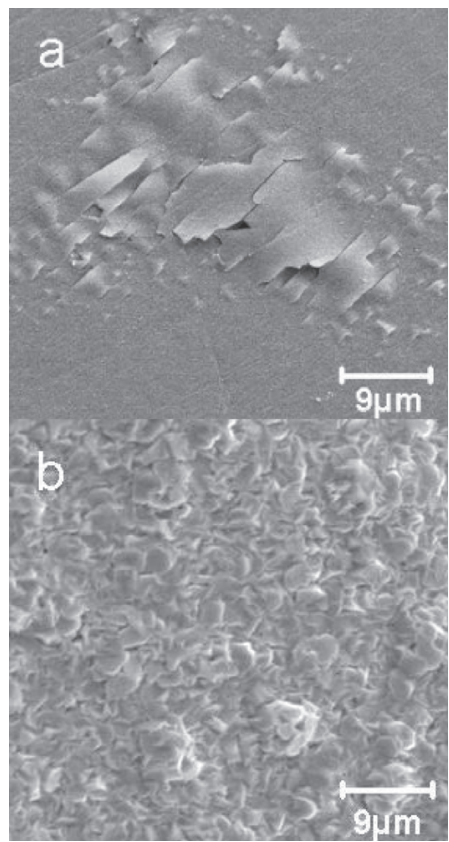

Figura 5. (a) Estágio inicial de formação do seleneto de cobre sobre cobre liso tratado com ácido nítrico. Aresta: $45 \mu \mathrm{m}$; (b) morfologia de um filme de seleneto de cobre sobre cobre rugoso, com espessura nominal de 3,2 $\mu \mathrm{m}$, obtido pela técnica de deposição seriada. Aresta: $45 \mu \mathrm{m}$

Porém, o filme obtido após 50 min não é aderente. Nas situações em que isto acontece, observam-se manchas mais escuras que o filme, possivelmente material incrustado nas cavidades.

A espessura máxima conseguida neste ponto das investigações foi pouco mais de $1 \mu \mathrm{m}$. No uso de seleneto de cobre em aplicações tecnológicas, convém uma espessura maior. Propõe-se aqui uma metodologia que consiste em intercalar um período de descanso alternado com o período de crescimento. Nestas condições, é possível o crescimento de filmes mais espessos e aderentes. Enquanto na técnica exclusivamente por DBQ o crescimento de filmes aderentes é limitado em cerca de 50 min, na deposição seriada o tempo de DBQ pode ser estendido até a obtenção de um filme aderente com espessura nominal de $5 \mu \mathrm{m}$. A Figura $5 \mathrm{~b}$ mostra a superfície de um filme preparado pelo processo de deposição seriada, enquanto que a Figura 6 mostra o efeito do tempo de descanso na cinética de crescimento do filme.

$\mathrm{O}$ aparecimento das manchas anteriormente mencionadas depende de $t_{D}$ e de $t_{D B Q}$. No intervalo de $t_{D} \leq 2 \mathrm{~h}$, pode-se generalizar que quanto maior for $t_{D}$, maior é o $t_{D B Q}$ necessário para o aparecimento das manchas. Além deste intervalo, as manchas aparecem mais rapidamente. Filmes homogêneos foram produzidos usando $t_{D}$ de $2 \mathrm{~h}$.

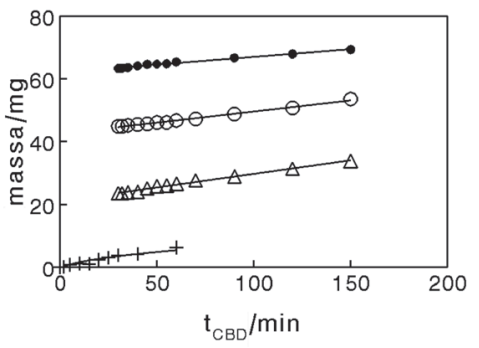

Figura 6. Comparação das curvas de crescimento do seleneto de cobre sobre cobre rugoso produzido pelas técnicas de $D B Q$ e deposição seriada. Legenda: $+: t_{D}=0 ; \Delta: t_{D}=30 \mathrm{~min} ; \bigcirc: t_{D}=1 \mathrm{~h} ; \mathrm{O}_{D}=2 \mathrm{~h}$. Substrato com $6 \mathrm{~cm}^{2}$ de área geométrica. As figuras foram propositadamente deslocadas em 0, 20, 40 e $60 \mathrm{mg}$, respectivamente, para facilitar a visualização

\section{CONCLUSÃO}

Filmes aderentes de $\mathrm{Cu}_{2-\mathrm{x}}$ Se com até $5 \mu \mathrm{m}$ de espessura podem ser produzidos pela técnica de deposição seriada $\left(t_{D B Q}=35\right.$ min e $t_{D}$ = $120 \mathrm{~min}$ ) sobre superfície rugosa de cobre decapado quimicamente. A decapagem eletroquímica do cobre é relevante para a aderência do filme quando o substrato é liso. $\mathrm{O} \mathrm{pH}$ e a presença de hidrazina não influenciam na composição do filme. O modelo de LLS aplicase satisfatoriamente aos filmes preparados sobre ouro, carbono vítreo e titânio. A resistência de transferência eletrônica entre o filme e o carbono vítreo é da ordem de $30 \Omega$, similar ao resultado de Lange et $a l .{ }^{21}$. Sobre titânio, esta resistência é consideravelmente menor $(0,4 \Omega)$, mas os filmes não são aderentes.

\section{AGRADECIMENTOS}

Parte de trabalho contou com apoio financeiro do CNPq (processo 477150/2001-2). T. M. Arantes agradece bolsa de Iniciação Científica PIBIC; A. C. Rabelo agradece bolsa de Iniciação Científica oferecida pela Cargill Agrícola S.A.

\section{REFERÊNCIAS BIBLIOGRÁFICAS}

1. Zainal, Z.; Nagalingam, S.; Loo, T. C.; Mater. Lett. 2005, 59, 1391.

2. Stanbery, B. J.; Crit. Rev. Solid State Mater. Sci. 2002, 27, 73.

3. Chakrabarti, D. J.; Laughlin, D. E.; Alloy Phase Diagrams 1981, 2, 305.

4. García, V. M.; Nair, P. K.; Nair, M. T. S.; J. Cryst. Growth 1999, 203, 113.

5. Lakshmi, M.; Bindu, K.; Bini, S.; Vijayakumar, K. P.; Kartha, C. S.; Abe, T.; Kashiwaba, Y.; Thin Solid Films 2000, 370, 89.

6. Lakshmi, M.; Bindu, K.; Bini, S.; Vijayakumar, K. P.; Kartha, C. S.; Abe, T.; Kashiwaba, Y.; Thin Solid Films 2001, 386, 127.

7. Lippkow, D.; Strehblow, H. H.; Electrochim. Acta 1998, 43, 2131.

8. Zhang, W.; Zhang, X.; Zhang, L.; Wu, J.; Hui, Z.; Cheng, Y.; Liu, J.; Xie, Y.; Qian, Y.; Inorg. Chem. 2000, 39, 1838.

9. Kemell, M.; Salonieme, H.; Ritala, M.; Leskelä, M.; Electrochim. Acta 2000, $45,3737$.

10. Ka, O.; Alves, H.; Dirnstorfer, I.; Christmann, T.; Meyer, B. K.; Thin Solid Films 2000, 361-362, 263.

11. Tutle, J. R.; Ward, J. S.; Berens, T. A.; Mater. Res. Soc. Proc. 1996, 426, 143.

12. Ward, J. S.; Ramanathan, K.; Hasoon, F. S.; Coutts, T. J.; Keane, J.; Contreras, M. A.; Moriarty, T.; Noufi, R.; Prog. Photovolt. Res. Appl. 2002, 10, 41.

13. Lewrenz, H. J.; Jungblut, H.; Photovoltaik, Springer Verlag: Berlin, 1995, p. 79.

14. http://www.nedo.go.jp/english/index.html, acessada em Abril 2006.

15. http://www.space.t.u-tokyo.ac.jp/cubesat/mission/V/index-e.html, acessada em Outubro 2006

16. Herrero, J.; Gutièrrez, M. T.; Guillén, C.; Doña, J. M.; Martínez, M. A.; Chaparro, A. M.; Bayón R.; Thin Solid Films 2000, 362, 28.

17. Myung, N.; Tacconi, N. R.; Rajeshwar, K.; Electrochem. Commun. 1999, 1, 42.

18. Dhanam, M.; Manoj, P. K.; Prabhu, R. R.; J. Cryst. Growth 2005, 280, 425.

19. Etienne, A.; J. Electrochem. Soc. 1970, 117, 870; Bottecchia, O. L.; J. Braz. Chem. Soc. 1998, 9, 515.

20. Pathan, H. M.; Lokhande, C. D.; Amalnerkar, D. P.; Seth, T.; Surf. Sci. 2004, $211,48$.

21. Lange, B.; Lovric, M.; Scholz, F.; J. Electroanal. Chem., 1996, 418, 21

22. Bhattacharya, R. N.; J. Electrochem. Soc., 1983, 138, 2040.

23. Bottecchia, O. L.; Relatório de Atividades de Pós-Doutorado, CNPq 290049/94-6, Technische Hochschule Darmstadt, Alemanha, 1996.

24. Doña, J. M.; Herrero, J.; J. Electrochem. Soc. 1995, 142, 764.

25. Ishikawa, Y.; Kido, O.; Kimura, Y.; Kurumada, M.; Suzuki, H.; Saito, Y.; Kaito, C.; Surf. Sci. 2004, 548, 276.

26. Schimmel, M. I.; Bottecchia, O. L.; Wendt, H.; J. Appl. Electrochem. 1998, $28,299$.

27. Roggendorf, W.; Galvanoténica Prática, Földes, P. A., trad.; Ed. Polígono: São Paulo, 1973, p. 239

28. Braune, H.; Hellwege, H.; Z. Phys. Chem. 1924, A110, 147; Braune, H.; Kahn, O.; Z. Phys. Chem., 1924, A112, 270, em Gmelins Handbuch der anorganischen Chemie, System-Nr. 60, Chemie Verlag: Berlim, 1936, p. 603.

29. Lakshmi, M.; Bindu, K.; Bini, S.; Vijayakumar, K. P.; Sunda-Kartha, C.; Abe, T.; Kashiwaba, Y.; Thin Solid Films 2001, 386, 127.

30. Wagner, C. C.; Z. Phys. Chem. 1936, B21, 25.

31. Bottecchia, A. L. ; Raslan, A.; Anais do XXXVII Congresso da Associação Brasileira de Química, São Luís, Brasil, 1998. 